\title{
A GESTÃO ESCOLAR EM FOCO: REFLEXÕES PRELIMINARES
}

Elisangela Aparecida Bulla Ikeshoji, Adriana Aparecida de Lima Terçariol, Adriano Rodrigues Ruiz

Universidade do Oeste Paulista - UNOESTE, Mestrado em Educação, Presidente Prudente - SP. E-mail: ikeshoji@uol.com.br

\section{RESUMO}

$\mathrm{Na}$ escola a gestão deve ser voltada para atender o aspecto fundamental, a educação. Sendo elemento essencial, o ser humano, sujeito de sua própria formação. A partir dessa perspectiva, o presente artigo apresenta como principal finalidade analisar o papel do gestor e a gestão na instituição educacional, bem como discutir a cultura como elemento desse processo. Para tanto, foi desencadeado uma pesquisa bibliográfica, adotando como referência trabalhos realizados por autores renomados na área. Como principal resultado este estudo exploratório ofereceu subsídios para o planejamento de uma análise mais aprofundada, na qual os pesquisadores desenvolverão uma pesquisa de abordagem qualitativa, do tipo estudo de caso, junto ao Programa de PósGraduação em Educação - Mestrado - da Universidade do Oeste Paulista (UNOESTE), com o propósito de desvelar, por meio da técnica do Discurso do Sujeito Coletivo (DSC), como o gestor e professores compreendem a gestão e se posicionam sobre o assunto.

Palavras-chave: Gestão, Cultura, Escola, Educação, Formação.

\section{MANAGEMENT SCHOOL FOCUS: PRELIMINARY THOUGHTS}

\begin{abstract}
In school management should be geared to meet the fundamental aspect, education. Essential for the human being, the subject of his own training. From this perspective, this paper has as main purpose to analyze the role of the manager and managing the educational institution as well as discuss culture as part of this process. To this end, a literature search was triggered, taking as a reference work by renowned authors in the field. The main result of this exploratory study offered support for planning for deeper analysis, in which researchers will develop a qualitative approach, the case study type, next to the Post-Graduate Education - MSc - University of the West Paulista (UNOESTE), with the purpose of revealing, through the technique of the Collective Subject Discourse (CSD), as the manager and teachers understand the management and position themselves on the subject.
\end{abstract}

Keywords: Management, Culture, School, Education, Training. 


\section{INTRODUÇÃO}

$\mathrm{Na}$ escola as relações entre docentes e alunos, assim como de todos os envolvidos dentro desse contexto devem convergir para um propósito pedagógico, a educação. Nas organizações as relações entre empregado e empregador decorrem da compra e venda da força do trabalho, não favorecendo desse modo o desenvolvimento de relações mais profundas entre esses profissionais. Em ambos os casos, as limitações das ações humanas podem existir.

Ao ter consciência dessas limitações, o ser humano deve ter um olhar observador, analítico e crítico, seja na vida pessoal ou profissional, em busca de percorrer um caminho que torne possível chegar aos objetivos pretendidos. Numa organização empresarial o modo de ser e de se fazer se volta exclusivamente para o fabricar de um produto, diferentemente, na instituição escolar o modo de ser e de fazer está intimamente ligado à formação do estudante, como ser humano. A diferença está na riqueza proporcionada pela escola, o se fazer humano na ação pedagógica.

Este fazer humano requer abertura para o ser, enquanto o expor das crenças, valores, sentimentos pessoais, nesta partilha se compartilhar coletivamente a responsabilidade assumida do ser docente. Neste contexto, interno e externo ao humano é que o docente desenvolve o seu trabalho e o seu modo de atuação traduz e expressa valores. $\mathrm{Na}$ expressão destes valores, assim como das opiniões, dos estilos é que se constitui o "humano coletivamente organizado" (LÜCK, 2011, p. 24).

É no coletivo que se dá o resultado das somas das partes. Por isso, é importante o gestor observar, analisar e interpretar os elementos como valores, crenças, estilos, ações que resultam das ações conjuntas dos docentes, que expressam a cultura da instituição. De maneira que a cultura da instituição favoreça atingir os objetivos educacionais, mas quais são estes objetivos? Qualidade de ensino, reprodução do conhecimento, formação do aluno como pessoa? Segundo os objetivos que se pretendem atingir, um caminho será trilhado, uma estratégia será adotada e o gestor é agente fundamental, o elo para conduzir a dimensão de trabalho coletivamente organizado dos docentes rumo à alcançar os objetivos da escola, a educação.

Será 0 gestor 0 agente que se utilizará de meios burocráticos, advindos dos processos empresariais para lidar com a educação; agilizará o processo decisório tendo por base a centralização de poder; ou se pautará sobre apenas ao cumprimento das leis, normas, estabelecidas? (VIEIRA; ALMEIDA; ALONSO, 2003). De acordo com suas crenças e valores, o gestor vai assumir uma postura para atingir os objetivos 
educacionais e consequentemente pode considerar ou não o "humano coletivamente organizado" (LÜCK, 2011, p. 24) em suas ações.

Transitar dentre estas nuances, em particular na escola, propicia investigar como o diretor e os docentes percebem o modelo de gestão vigente numa instituição de ensino, assim como compreender as razões da gestão diante das circunstâncias do cotidiano. Nesse cenário, neste artigo os pesquisadores se propõem a analisar o papel do gestor e a gestão na instituição educacional, bem como discutir a cultura como elemento da gestão, por meio de um estudo bibliográfico, adotando como referência estudos realizados por autores renomados na área.

\section{REFLETINDO SOBRE O PAPEL DO GESTOR E A GESTÃO NA ESCOLA}

Os erros e ilusões fazem parte da mente humana (MORIN, 2000), se considerar que ao reconstruir algo visto, seja pela linguagem ou pensamento pode ocorrer uma tradução ilusória. Complementa Marx (2007) sobre a ideia falsa que o homem tem de si, da vida e do mundo. Estende-se assim, à questão da gestão escolar, que não é neutra, mas deve compreender sua intencionalidade. E por isso, o gestor deve pressupor que seu papel está em planejar, coordenar, controlar (CHIAVENATO, 2003), assim como atuar sobre valores, crenças, sentimentos, emoções, de maneira tal que provoque reações dos docentes para o enfrentamento dos desafios escolar, sendo estas importantes e favorecedoras para que objetivos educacionais sejam alcançados (LÜCK, 2011).

O gestor deve desenvolver seu trabalho e compreender o efeito deste, tendo por base o processo da gestão. Assim como o docente ao entender o funcionamento da gestão participa de forma mais ativa e efetiva nas ações da escola (LÜCK, 2011).

Sendo assim, antes de avançar em alguns aspectos da gestão, enunciar os termos Administração e Gestão parece ser bastante oportuno. Administração é o processo de planejar, organizar, dirigir e controlar pessoas para alcançar objetivos organizacionais (CHIAVENATO, 2003). Voltase mais como uma função administrativa, refere-se aos princípios de organizar, estruturar e controlar os recursos disponíveis (LIBÂNEO; OLIVEIRA; TOSCHI, 2012). A gestão implica atuar sobre as questões que envolvem as ações das pessoas, identifica-se como um empreendimento que visa à promoção humana, para atingir os objetivos organizacionais (LÜCK, 2011; LIBÂNEO; OLIVEIRA; TOSCHI, 2012). No entanto, em ambos os casos, Libâneo, Oliveira e Toschi (2012) nomeiam que estas organizações são 
unidades sociais, destinam-se a alcançar determinados objetivos, embora cada qual com objetivos específicos e distintos.

Nas organizações empresariais, como unidades sociais, a função administrativa se sobressai, entende-se aqui que as pessoas são tratadas como recursos, assim como o dinheiro, a matéria-prima, o que as distingue das organizações escolares, unidades sociais voltadas à busca essencialmente da promoção e formação humana. Nesta última, as funções administrativas também estão presentes, sendo de total importância, no entanto não se constituem como o elemento essencial.

Entende-se assim que a gestão que emana no ambiente escolar deve ser norteada para a educação. Tendo a escola como essencial objetivo a educação, uma vez que favorece a formação do ser humano. Nela se sobressai a interação entre as pessoas, cujo desenvolvimento das potencialidades físicas, cognitivas, afetivas e atitudinais ocorre via o ensino e a aprendizagem (LIBÂNEO; OLIVEIRA; TOSCHI, 2012). Processo esse que o gestor precisa compreender para intervir.

O gestor tem o papel fundamental de lidar com as competências, os valores, as crenças de todos os envolvidos nas ações da escola, com o intuito de convergir os esforços para atingir os objetivos que devem ser comum, a educação. A valorização das relações entre todos os envolvidos nesse ambiente escolar deve ser primordialmente considerada, visto que é na diversidade que as ações precisam ser articuladas com vistas ao propósito maior.

Relevância que não ocorre na administração científica de Taylor, na qual valoriza-se o aperfeiçoamento dos métodos utilizados nos processos de produção, conhecido por Organização Racional do Trabalho (ORT), assim como os conceitos sobre a administração enquanto processo. Não existe a preocupação com o operário, quanto às várias consequências causadas pelo esforço humano repetitivo. Antes mesmo de Taylor iniciar os estudos dos problemas reais das organizações empresariais da sua época, visando torná-los uma ciência, a arte da administração já existia, milhares ou milhões de pessoas trabalharam nas construções das grandes pirâmides do Egito, cerca de 2500 a.C. Para atingir os objetivos que se pretendia, a coordenação e controle dos trabalhos realizados pelas pessoas, aplicou-se o que foi conhecido séculos depois, por uma ciência da administração (CHIAVENATO, 2003).

Sendo assim, é importante acenar que em vários momentos da história a preocupação não é de um olhar mais atento quanto às pessoas envolvidas no trabalho das organizações e instituições (públicas ou privadas). As organizações empresariais 
começam a perceber a importância das pessoas, na obtenção de seus objetivos e consequentemente contribuição nos resultados organizacionais, após a primeira metade do século $X X$, período conhecido por globalização dos mercados, mundialização, competitividade dentre vários outros termos (CHIAVENATO, 2003).

Entretanto, nas organizações empresariais, a preocupação se volta essencialmente ao processo produtivo que reflete e acaba por interferir no desenvolvimento da sociedade como um todo. Cabe à escola conhecer esse modo de produção e como ele se produz na sociedade, assim como desvelar de forma crítica para que se compreenda que as bases do sistema de produção é que reforça que o mundo precisa funcionar desta maneira (WELLEN; WELLEN, 2010).

Portanto, ainda segundo Wellen e Wellen (2010, p. 165), o ser humano "pode realmente não relacionar diretamente as negatividades do seu trabalho e de vida às imposições do seu patrão ou do sistema capitalista, mas essas determinações não passam incólumes na consciência do trabalhador". Se assim o é, melhor e mais favorável, a escola pode e deve contribuir para este desvelar. Sendo assim, é importante reconhecer e compreender as necessidades dos trabalhadores no mundo do trabalho e os permitir perceber as ligações que a formação educacional oferecida pela escola pode proporcionar ao levar a repensar este contexto da relação com o trabalho, no sistema de produção capitalista e transformar a realidade social (PISTRAK, 2002; LIBÂNEO; OLIVEIRA; TOSCHI, 2012).

Entender estas contradições sociais é essencial, pois desta maneira o gestor tem condições para fazer da escola um contexto onde não se reproduza os reflexos das estruturas da sociedade capitalista, mas que se reflitam estas interferências conscientes, contribuindo para uma ação pedagógica mais abrangente e consequentemente para uma formação emancipadora.

Segundo Libâneo, Oliveira e Toschi (2012) estudos indicam algumas características organizacionais que podem ser utilizadas no contexto escolar. Porém, cabe a ressalva, é importante considerar que as escolas não são iguais e por isso nem sempre é possível generalizar, mas quando bem compreendidas e geridas, determinadas características, podem interferir no modo de ser e de se fazer da escola. Logo, as características organizacionais quando compreendidas e adequadamente adaptadas, pelo gestor brotam efeitos positivos. Quando este consegue implementá-las para promover e guiar as ações dos docentes, com vistas a prepará-los melhor em sua atividades para assim ter clareza quanto ao seu complexo papel na 
docência refletindo na preparação de seus objetivos em sala de aula e conteúdos; projeto pedagógico bem definido, onde reside o consenso mínimo entre direção e corpo docente; bom clima de trabalho; papel significativo da direção e coordenação pedagógica; equipe disposta a inovar sem perder a identidade, atingem melhores resultados educacionais.

E para entender esta busca do em comum, passa por compreender a cultura da instituição escolar como elemento da gestão. A seguir abordarmos com mais detalhes essa questão.

\section{A CULTURA DA INSTITUIÇÃO ESCOLAR COMO ELEMENTO DA GESTÃO}

O conceito de cultura proposto por Schein (2009) se volta ao que pode ser chamado de abstração, pois não é possível ver as forças internas que causam os comportamentos dos seres humanos, apenas o resultado deles. Portanto, a cultura é intrínseca em cada ser humano e sua construção e transformação se dá na relação com o outro. Entender aspectos sobre valores, crenças e práticas, originário de elementos não visíveis, porém essenciais, apresenta-se como terra fértil de profundos e complexos significados.

Nessa perspectiva de que a cultura é interna ao ser humano segue uma linha antropológica e não histórica. Antropológica, pois o ser humano carrega consigo valores, crenças e práticas num determinado momento da história e em seu tempo, diferentemente, ocorre num outro momento quando ele passa a não mais existir. Esse que compõe as sociedades e passam então pelo que pode ser entendido como transformações culturais (TEIXEIRA, 2002). Além disso, a cultura pode ser compreendida como um processo dinâmico, que ao mesmo tempo é contínuo e ativo, sendo caraterística importante de construção da realidade. A cultura pode ser entendida como a personalidade, seja da organização empresarial, da escola ou do ser humano (SCHEIN, 2009; LÜCK, 2011).

Os valores e crenças da cultura individual, o que Teixeira (2002) denomina de instituinte, quando se relaciona com os aspectos da vida cotidiana, o que ainda não se institucionalizou, contribui e favorece na construção da cultura do grupo ou da sociedade. E os códigos, normas, rituais e costumes, denominados por Teixeira (2002) como instituído, que faz parte da cultura, entende-se que está posto. A autora argumenta que instituído e instituinte são polos e se relacionam de tal maneira que a cultura resulta da relação entre eles. Porém, para compreendermos uma cultura individual, assim como de uma organização, torna-se necessário entender que as culturas surgem segundo três aspectos (SCHEIN, 
2009): (1) crenças e valores individuais; (2) experiências pessoais e as experiências de aprendizagem ao se relacionar com o outro; (3) novas crenças e valores que se desenvolve no se relacionar com o outro, já integrante do ambiente ou que chega de fora, um novo ingressante. É nesse sentido, que o estudo proposto será desenvolvido.

Portanto, ao se voltar para a questão da cultura, a liderança que Schein aborda pode ser compreendida no papel do diretor da instituição escolar, visto que foi escolhido pelos seus pares como o representante do grupo.

Entende-se, portanto, que um dos papéis do diretor é perceber quais são os valores e crenças que compõem a cultura da instituição onde está inserido. Ao identificar esses elementos o gestor tem possibilidade de potencializá-los, de acordo com o planejamento pretendido pela instituição escolar, com o propósito de alcançar o essencial objetivo da escola, segundo Lück (2011, p. 17), que é a aprendizagem dos alunos e sua formação. Para Fraga (2009) esta compreensão da gestão é denominada de inclusão, pois assim o gestor é tido como sensível e coerente quando considera e aprecia significativamente os aspectos relevantes da cultura individual, com a finalidade de atingir o objetivo da escola. Dessa maneira, a relação entre o diretor e sua ação, ou seja, do sujeito e o objeto de ação parte de uma intenção cujo critério de relevância da ação administrativa não se sobrepõe ao aspecto humano (FRAGA, 2009; LÜCK, 2011).

\section{CONSIDERAÇÕES FINAIS}

Considerando que as organizações escolares são unidades sociais e sofrem forte impacto dos elementos culturais é importante "destacar a cultura organizacional como um conceito central na análise da organização das escolas, significa buscar compreender a influência das práticas culturais dos indivíduos e sua subjetividade sobre as formas de organização e de gestão escolar" (LIBÂNEO; OLIVEIRA; TOSCHI, 2012, p. 439).

Entende-se, portanto, que um dos papéis do diretor é perceber quais são os valores e crenças que compõem a cultura da instituição onde está inserido. Identificar esses elementos e aproveitando da melhor maneira possível que favoreça alcançar o propósito essencial da escola, a educação, no que tange a aprendizagem dos alunos e sua formação.

Para Fraga (2009) essa compreensão da gestão é denominada de inclusão, pois assim o gestor é tido como sensível e coerente quando considera e aprecia significativamente os aspectos relevantes da cultura individual, com a finalidade de atingir o objetivo da escola. Dessa maneira, a 
relação entre o diretor e sua ação, ou seja, do sujeito e o objeto de ação parte de uma intenção cujo critério de relevância da ação administrativa não se sobrepõe ao aspecto humano (FRAGA, 2009; LÜCK, 2011).

A partir dessa perspectiva, os pesquisadores motivados com o estudo desta temática darão continuidade aos estudos, ampliando esta análise, por meio de uma pesquisa a ser realizada no âmbito do Programa de Pós-Graduação em Educação Mestrado - da Universidade do Oeste Paulista (UNOESTE), com o desenvolvimento de uma pesquisa de mestrado, cujo objetivo será identificar e analisar como a gestão escolar é compreendida, sob a perspectiva do gestor e docentes de uma instituição pública de ensino profissional e tecnológico, localizada no interior do estado de São Paulo.

A pesquisa assumirá uma abordagem qualitativa, do tipo estudo de caso. Para a análise dos dados utilizar-se-á a técnica do Discurso do Sujeito Coletivo (DSC).

\section{REFERÊNCIAS}

CHIAVENATO, I. Introdução à teoria geral da administração: uma visão abrangente da moderna administração das organizações. Rio de Janeiro: Elsevier, 2003.

FRAGA, V. F. Gestão pela formação humana: uma abordagem fenomenológica. Barueri, 2009.

LIBÂNEO, J. C; OLIVEIRA, J. F.; TOSCHI, M. S. Educação escolar: políticas, estruturas e organização. São Paulo: Cortez, 2012.
LÜCK, H. Gestão da cultura e do clima organizacional da escola. 2. ed. Petrópolis: Vozes, 2011. (Série cadernos de gestão, v.v)

MARX, K. A ideologia alemã. São Paulo: Martins Fontes, 2007. p.3-4.

MORIN, E. Os sete saberes necessários à educação do futuro. São Paulo, SP: Cortez; Brasilía, DF: UNESCO, 2000

PISTRAK, M. Fundamentos da escola do trabalho. São Paulo: Expressão Popular, 2002.

SCHEIN, E. H. Cultura organizacional e liderança. São Paulo: Atlas, 2009.

TEIXEIRA, L. H. G. Cultura organizacional e projeto de mudança em escolas públicas. Campinas: Autores Associados, São Paulo: UMESP/ANPAE, 2002.

VIEIRA, A. T.; ALMEIDA, M. E. B.; ALONSO, M. (orgs). Gestão educacional e tecnologia. São Paulo: Avercamp, 2003.

WELLEN, H.; WELLEN, H. Gestão organizacional e escolar: uma análise crítica. Curitiba: Ibpex, 2010.

Recebido para publicação em 11/08/2014 Revisado em 03/09/2014

Aceito em 15/09/2014 